\title{
On the environmental fracture of polymethylmethacrylate
}

Y. W. MAl*

Department of Mechanical Engineering, University of Hong Kong, Hong Kong

Crack propagation of PMMA in some liquid environments is described for various testing conditions, such as fixed load, fixed displacement and monotonically increasing displacement. Fracture mechanics concepts have been used successfully in analysing the results. When continuous stable cracking is achieved, values of fracture toughness $(R)$ for PMMA under these loading conditions are obtained as a function of crack velocity $(L)$ using the method of Gurney and Hunt [11]. For crack velocities greater than $10^{-2} \mathrm{~mm} \mathrm{sec}^{-1}$, the fracture toughness values in the environments are increased when compared with the corresponding air results. Unique relationships between $R$ and $i$ have been shown to exist for cracking in ethanol and carbon tetrachloride.

\section{Introduction}

Fracture of PMMA in hostile environments is an interesting but complex problem. Previous papers on the subject are those of Andrews and Bevan [1, 2], Andrews and Levy [3] and Marshall et al. [4].

The ability of certain liquids to cause swelling and hence softening of glassy plastics such as PMMA is well known. Crazes are formed when the softened material undergoes cavitation due to a sufficiently high dilatant stress [2, 3 5]. "Compatible" liquids can cause remarkable reductions in the glass transition temperature $\left(T_{\mathrm{g}}\right)$ and hence lower the stress necessary for craze formation. For relatively "incompatible" liquids, appreciable swelling may also occur at stress concentration sites such as flaws and cracks where a large local dilatant stress exists [6]. As an example, Fig. 1 records some experimental results [7] showing the remarkable reduction of microhardness of PMMA at the crack tip region due to softening by the liquid environments.

The mechanics and mechanisms controlling craze and crack propagation in edge-cracked PMMA tensile specimens immersed in a variety of liquids have been discussed in [1-4]. Using fracture mechanics criteria, a minimum surface energy requirement $\left(\mathscr{T}_{0}\right)[1,2]$ or equivalently a threshold stress intensity factor $\left(K_{\mathrm{m}}\right)$ [4] for crack propagation or craze formation may be obtained by measuring the critical applied stress $\left(\sigma_{c}\right)$ necessary to cause a discontinuity of length $(c)$ to spread. The governing equations are given by

$$
K_{\mathrm{m}}{ }^{2}=2 E \mathscr{T}_{0}=\sigma_{\mathrm{c}}{ }^{2} Z^{2} \mathcal{c}
$$

where $E$ is the Young's modulus and $Z$ the finite width correction factor for the edgecracked specimen.

Craze growth kinetics in edge-cracked PMMA test pieces immersed in methanol under constant load have been studied by Marshall et al. [4]. They found that the craze initiation and growth characteristics were dependent on the initial applied stress intensity factor $K_{0}\left(=\sigma_{c} Z c_{0}{ }^{1 / 2}\right)$ and not on the applied stress $\sigma_{0}$. Two distinct types of craze growth behaviour were observed depending on the magnitude of $K_{0}$, one type loading to craze arrest and the other to complete fracture. In a more recent treatment [3], Andrews and Levy discovered that in the region where a craze spread at constant velocity, the net section applied stress was the velocity controlling parameter regardless of the presence or absence of a starter crack. Increasing the net section stress would increase the craze tip velocity. The effect of $c_{0}$ on craze propagation was only a "memory" effect [3]. These findings imply that the $K_{0}$ dependence of craze velocity is 


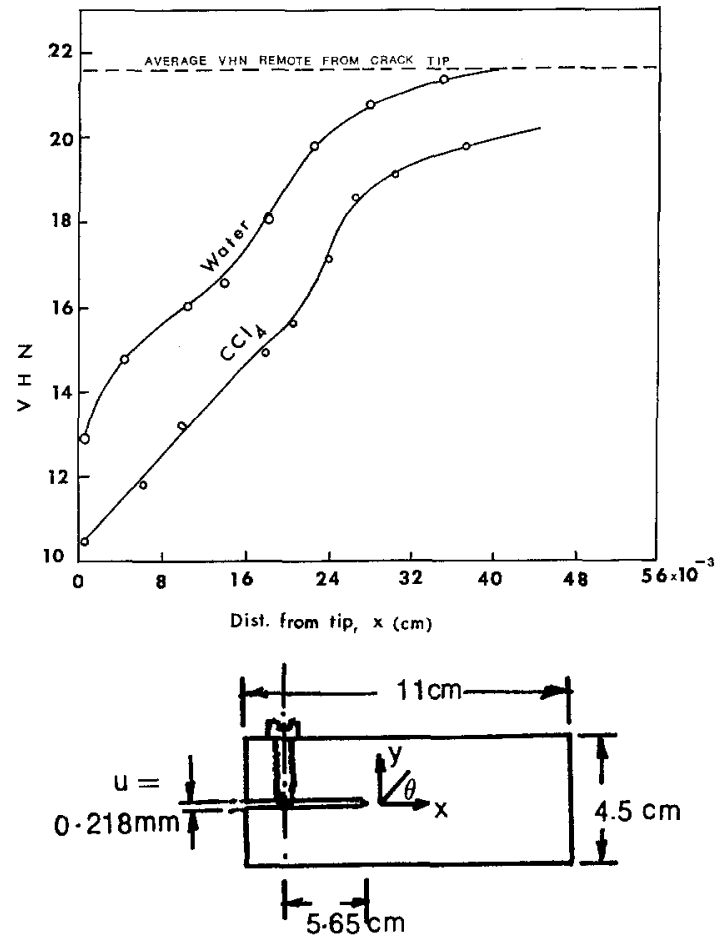

TIME OF EXPOSURE $=18.5 \mathrm{~h}$

Figure 1 Variation of (Vicker) microhardness along crack line showing effects of softening.

not necessarily due to the instantaneous crack tip opening displacement of the starter crack as originally suggested in Marshall et al. [4].

Temperature is a vitally important parameter in solvent-stress crazing [1-3]. For a given environment, Andrews and Bevan $[1,2]$ have shown that at relatively low temperatures $\left(T<T_{\mathrm{e}}\right), \mathscr{T}_{\mathbf{0}}$ decreases rapidly with increasing temperature up to a characteristic temperature $T_{\mathrm{c}}$. For $T \geqslant T_{\mathrm{e}}, \mathscr{T}_{0}$ assumes a minimum value $\mathscr{T}_{0}{ }^{*}$ which is temperature independent. Further experimental evidence [5] shows that $T_{\mathrm{e}}$ is close to the glass transition temperature, $T_{\mathrm{g}}$, of the swollen material at the crack tip. This temperature dependence behaviour of $\mathscr{T}_{0}$ has been shown to conform to a cavitation criterion for craze formation $[2,5]$.

While attention in all previous work is focused on the initiation and propagation of a craze or crack under essentially constant loads (e.g. Marshall et al. [4]), relatively little is known about the mechanical behaviour of these environment-induced crazes or cracks when

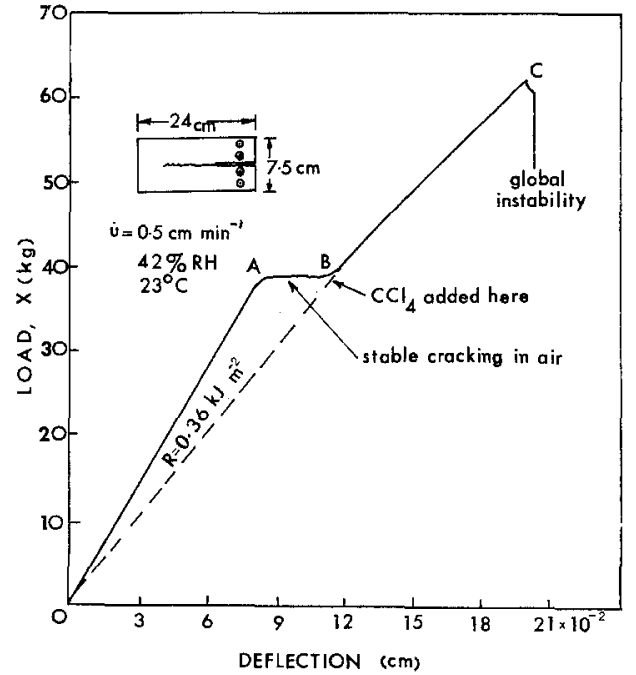

Figure 2 Effects of environments on cracking under monotonic increasing displacements.

subject to other loading conditions such as cyclic loads and monotonic increasing loads (or displacements). The first data on fatigue craze propagation in PMMA immersed in methanol were obtained by Marshall and Williams [8] under a range of loading frequencies. Recently, the present author [9] has also presented some experimental data on the fatigue crack growth rate of PMMA in ethanol and carbon tetrachloride. Benbow [10], on the other hand, investigated the effect of absorption of water on the specific energy for cracking in PMMA under monotonic increasing displacements. He found that the specific work for fracture was approximately four times as much as that in air. However, his cracking experiments were unstable so that cracks were jerky. A parallel experiment as recorded in Fig. 2 shows the results of cracking a $6 \mathrm{~mm}$ thick PMMA Outwater testpiece by bending in an Instron testing machine. In air, where cracking was stable, continuous and smooth, the fracture load was approximately constant (AB). However, as soon as carbon tetrachloride was introduced at the crack tip (B), the crack was arrested and the new fracture load considerably increased. This was followed by unstable cracking. These experimental results are in general agreement with those observed by Benbow [10]. It was not readily understood why cracking (under monotonic increasing displacements) was unstable and the specific work of fracture increased. However, Gurney and Hunt [11] suggested that in the presence of a 
solvent the fracture toughness* $(R)$ of the crack tip material would be apparently increased, (probably due to the blunting of the tip of the craze wedge [2] under increasing load or displacement). When the crack ran away from the swollen zone and into the virgin material with negligible absorption and hence a lower $R$ value, cracking was unstable because $\mathrm{d} R / \mathrm{d} A$ was negative, $A$ being the crack area. Some fundamental concepts on the stability of cracking are given in [11-17].

Other relatively unexplored areas include the strain rate or loading rate dependence of $\mathscr{T}_{0}$ for PMMA immersed in various liquids, the fracture of unnotched tensile specimens in the presence of organic solvents and the possible correlation of $R$ (or equivalently $\mathscr{T}$ ) with craze or crack speed $(L)$ at given temperatures and liquid environments.

In the present paper, continuous slow cracking of PMMA in the presence of a variety of liquid environments is discussed. The energy approach of Gurney and co-workers [11-14] to fracture mechanics is used for fracture measurements.

The research programme consists of two series of experiments conducted under different operating conditions of the testing machine. In the first series, environmental crack initiation and propagation experiments were carried out in an Instron testing machine with monotonic increasing displacements (i.e. $\delta u / u>0$ ). In the second series of experiments, the objective was to study, in the "subcritical" growth region, the effects of environment absorption on fracture when the displacement $(u)$ was held constant.

When stable cracking was achieved in these experiments, fracture toughness values were obtainable from the method of Gurney and Hunt [11] and expressible as a function over a useful range of crack velocity.

This paper also includes some experimental results showing the effects of absorption of organic solvents on the stress-break time relationship in "delayed" fracture experiments under constant load conditions.

\section{Experimental methods and results}

\subsection{Onset of crack growth in various environments}

Single edge notched specimens measuring 76

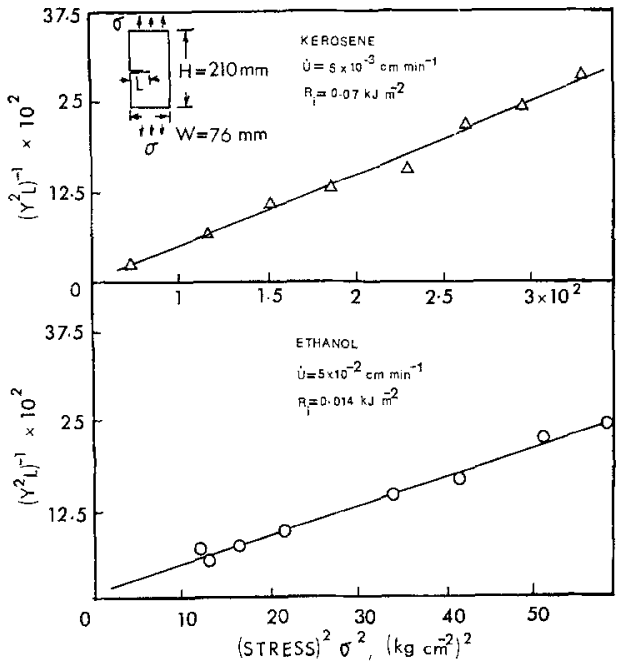

Figure 3 Onset of crack growth in kerosene and ethanol using SEN specimens.

$\mathrm{mm} \times 210 \mathrm{~mm}$ were cut from $6 \mathrm{~mm}$ thick Perspex sheets. A small edge notch was introduced halfway along one face of each specimen. The notch depth could be varied easily, and a precrack made by hitting with a razor. Only those specimens with properly oriented cracks were used.

The specimens were loaded as shown in the inset of Fig. 3. Continuous environment was maintained at the crack tip region with a small reservoir attached to the test section. Movement of the crack tip was monitored by a travelling microscope and the critical load to cause crack initiation at a given starter-crack length was recorded by the Instron testing machine. Fig. 3 shows the dependence of a critical stress requirement, for varying crack lengths, for the onset of crack growth in kerosene (cross-head speed, $\left.\dot{u}=0.005 \mathrm{~cm} \mathrm{~min}^{-1}\right)$ and ethanol $(\dot{u}=$ $\left.0.05 \mathrm{~cm} \mathrm{~min}^{-1}\right)$ at $45 \%$ R.H. and $296 \mathrm{~K}$. The linear relationship observed from these plots enables the crack initiation toughness $\left(R_{1}\right)$ in the liquid environments to be found from the following equation [18]

$$
E R_{\mathbf{i}}=\sigma^{2} L Y^{\varepsilon}
$$

where

$$
\begin{gathered}
Y=1.99-0.41(L / W)+18.70(L / W)^{2} \\
-38.48(L / W)^{3}+53.85(L / W)^{4}
\end{gathered}
$$

\footnotetext{
${ }^{*} R$ is a symbol used in Gurney [11] and is essentially equivalent to $2 \mathscr{T}$ as used in Andrews and Bevan [1, 2]. For crack propagation, $E R=p K^{2}$ where $p=1$ for plane stress and $\left(1-\nu^{2}\right)$ for plane strain. $\nu$ is Poisson's ratio. Hereafter, $R$ will be used throughout the paper.
} 


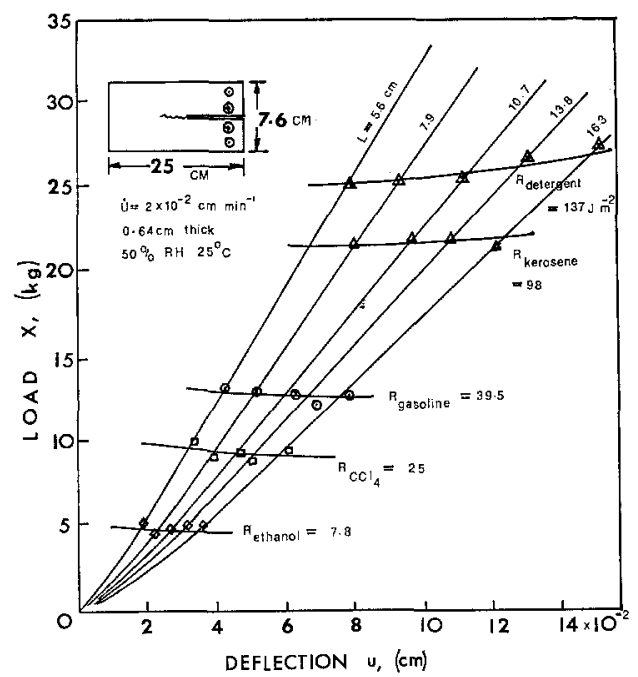

Figure 4 Crack initiation toughness in various liquid environments.

and $W$ is the width of the specimen, $L$ the initial edge crack length, $\sigma$ the applied critical stress to cause crack initiation and $E$ is determined experimentally at appropriate cross-head speeds.

These results show that in kerosene and ethanol the fracture toughness of PMMA for crack initiation $\left(R_{\mathrm{i}}\right)$ is 70 and $14 \mathrm{~J} \mathrm{~m}^{-2}$ respectively. Note that in air, $R_{\mathrm{i}}=280 \mathrm{~J} \mathrm{~m}^{-2}$ at $\dot{u}=0.05 \mathrm{~cm} \mathrm{~min}^{-1}$.

In another series of experiments, Outwater testpieces were used to study the phenomenon of onset of crack growth in Perspex when immersed in various other liquid environments. Fig. 4 summarizes the results for crack initiation toughness at $298 \mathrm{~K}$ in ethanol, carbon tetrachloride, gasoline, kerosene and detergent. These results suggest that $R_{\mathrm{i}}$ depends only on the environments and is independent of specimen geometry. However, for a constant environment, we have found that the crack initiation toughness is rate sensitive, being dependent on the crosshead speed of the testing machine. Fig. 5 shows this relationship for detergent, ethanol and carbon tetrachloride.

\subsection{Stable monotonic increasing displacement experiments in the Instron machine}

In the Introduction, we have shown that in monotonic loading tests (see Fig. 2), $R$ of PMMA for crack propagation in the liquid environment is apparently increased. However, because the experiments are unstable, it is

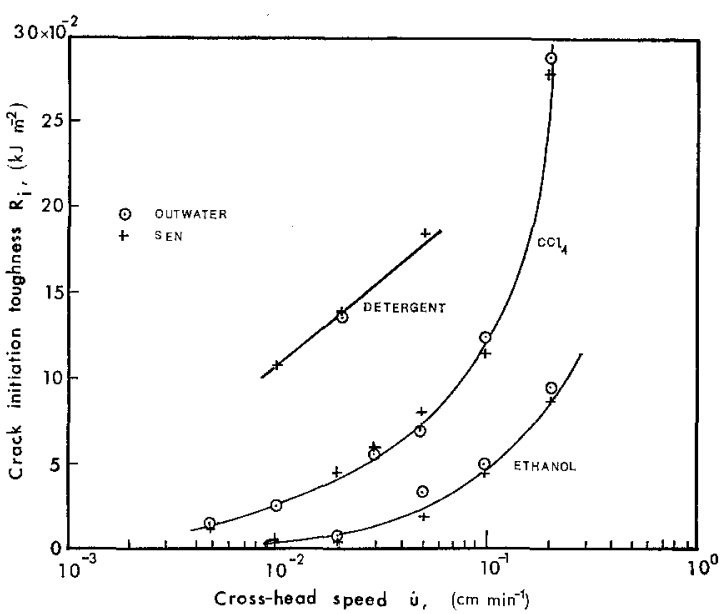

Figure 5 Effect of cross-head speed on crack initiation toughness in detergent, $\mathrm{CCl}_{4}$ and ethanol.

difficult to assess the fracture toughness of the material and to measure its corresponding propagation velocity. To promote stable cracking so that both $R$ and $\dot{L}$ can be simultaneously measured, the following methods have been tried.

Experiments have shown that for a given environment and test geometry continuous stable cracking was only achieved at certain cross-head speeds of the Instron machine, (e.g. for Outwater testpieces, $\dot{u}=0.01 \sim 0.05 \mathrm{~cm} \mathrm{~min}^{-1}$ ). Fig. 6 records the results of such an experiment in which continuous quasi-static cracking of PMMA in $\mathrm{CCl}_{4}$ is obtained in an Outwater testpiece. The test conditions were $58 \%$ R.H. and $296 \mathrm{~K}$. It may be seen that the fracture toughness $\left(0.57 \mathrm{~kJ} \mathrm{~m}^{-2}\right)$ when compared with the corresponding air results at similar testing conditions $\left(0.37 \mathrm{~kJ} \mathrm{~m}^{-2}\right)$ is definitely increased.

In some liquid environments crack propagation proceeds in a "quasi-stable" manner when the jerks indicating instabilities are small. The cracking experiment of PMMA in lubrication oil at $296 \mathrm{~K}$ as shown in Fig. 7 demonstrates this effect. Note that the environmental fracture toughness for propagation has also been apparently increased.

Alternatively, stable cracking experiments may be attained by using favourable test geometries which possess inherent good stabilities [14]. The following test configurations (see Fig. 8) have been used to give either stable or "quasi-stable" cracking in the environments listed in Table I:

(a) a cracked ring under diametrical compression; 


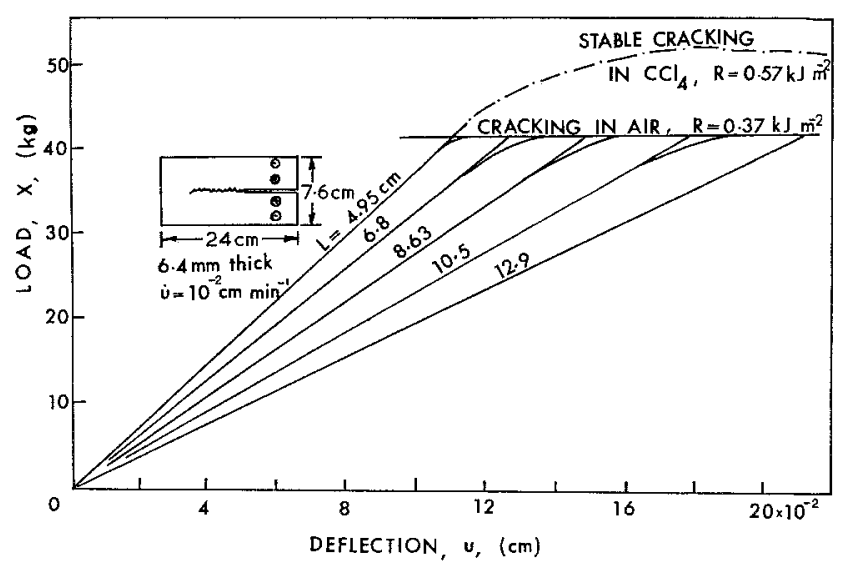

Figure 6 Quasi-static cracking of PMMA in $\mathrm{CCl}_{4}$ under monotonic increasing displacement.

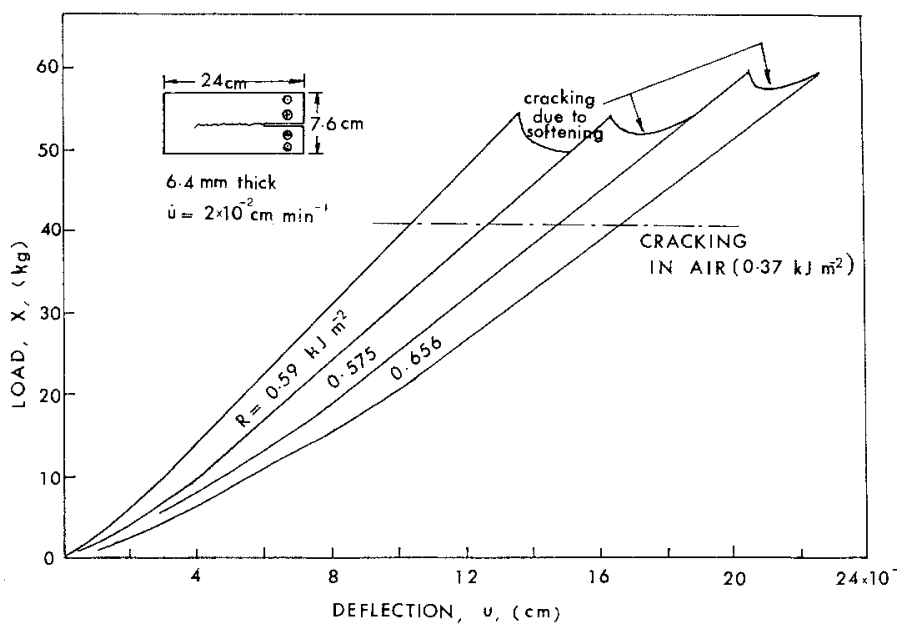

Figure 7 "Quasi-stable" cracking of PMMA in lubrication oil under monotonic increasing
TABLE I Comparison of fracture toughness of PMMA in various environments with stable crack propagation under monotonic increasing displacements. (Crack speed $=1 \sim 2 \times 10^{-1}$ $\mathrm{mm} \mathrm{sec}^{-1}$ )

\begin{tabular}{ll}
\hline Environment & Fracture toughness $\left(\mathrm{kJ} \mathrm{m}^{-2}\right)$ \\
\hline Air & 0.380 \\
Lubrication oil & 0.540 \\
Carbon tetrachloride & 0.600 \\
Tap water & 0.680 \\
Gasoline & 1.100 \\
Ethanol & 1.210 \\
Kerosene & 1.400 \\
\hline
\end{tabular}

(b) a rectangular plate-like testpiece with a centre hole of $25 \mathrm{~mm}$ diameter and an initial crack penetrated through the circumference; and

(c) plate-like testpieces with elastic adhesive tapes and reversible external stabilizers placed across the crack path.

Table I compares the values of $\mathrm{R}$ for PMMA ( $6 \mathrm{~mm}$ thick) cracking in various environments for crack speeds of $1 \sim 2 \times 10^{-1} \mathrm{~mm} \mathrm{sec}^{-1}$ and at 296 to $298 \mathrm{~K}$. These results indicate that depending on the Perspex/environment system, the fracture toughness varies accordingly. It is also interesting to note that the degree of surface roughening increases with the environments in the order shown. (i.e. higher $R$ values are associated with more rugged and coarse fracture surfaces.)

Finally, to study the effects, if any, of presoaking PMMA, six specimens of the Outwater type were left to soak in $\mathrm{CCl}_{4}$ and lubrication oil respectively for 2 weeks before testing in the Instron to fracture. Our experiments show that presoaking in these liquid environments has no appreciable effect on the material fracture toughness. 

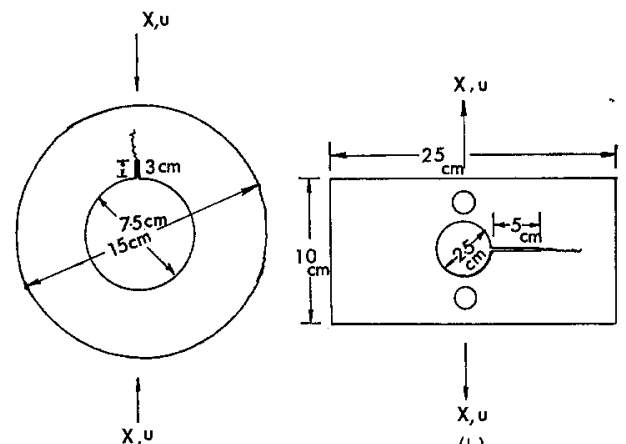

(b)

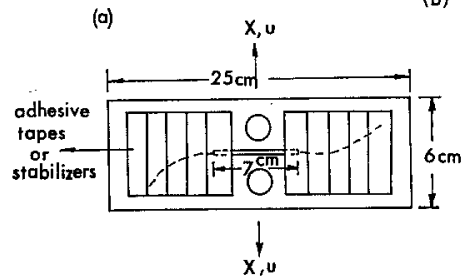

(c)

Figure 8 Specimens geometries with favourable geometrical stability factor used for quasi-static cracking in monotonic increasing displacement experiments.

\subsection{Fracture under constant loads and displacements \\ 2.3.1. Effects of absorption of organic solvents on delayed fracture under constant loads}

Tensile specimens with dimensions measuring $3 \mathrm{~mm} \times 2 \mathrm{~mm} \times 100 \mathrm{~mm}$ gauge length were made from PMMA sheets. Tests were performed at $298 \mathrm{~K}$ in an environmental chamber, with dead loads applied to the specimens giving the desired stress levels $\left(\sigma_{\mathrm{f}}\right)$. The times to break $\left(t_{\mathrm{f}}\right)$ were recorded. Results for two typical organic solvents, $\mathrm{CCl}_{4}$ and ethanol, are shown in Fig. 9. Each data point on the curve represents the average value of five similar tests. The relation for these plots follows the equation governing the fracture kinetics of solids under dead load conditions as proposed by Zhurkov [19]. It is also obvious from these results that ethanol is more aggressive to PMMA than $\mathrm{CCl}_{4}$ under this loading situation. Experiments were also made on geometrically similar specimens having a size factor of 1.50 and their results superimposed on Fig. 9. It is noted that a longer life is anticipated for geometrically larger specimens under the same applied stress. Such a size effect associated with absorption of environments has not been reported previously.

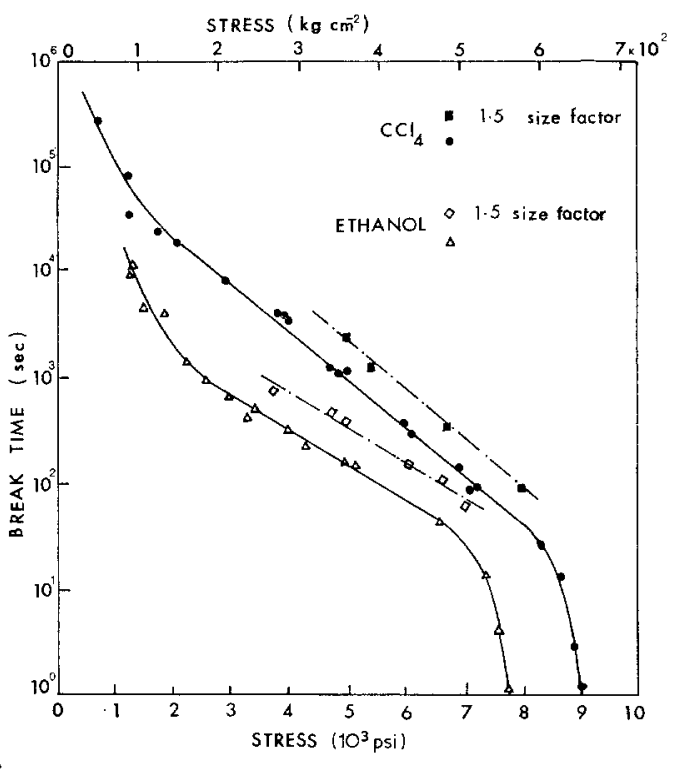

Figure 9 Stress-break time of PMMA in ethanol and carbon tetrachloride.

\subsubsection{Fracture under sustained displacements in environments}

The behaviour of "subcritical" or slow crack growth of PMMA in the presence of liquid environments under sustained displacements is reported in this section. All experiments were performed on a simple crack propagation apparatus as shown in Fig. 10*. Essentially, this consists of two erected extension steel bars which are pulled apart on application of a displacement monitored by the micrometer screw. The load $(X)$ at a given displacement $(u)$ is indicated by the movement of the dial gauge mounted as shown and converted by a calibration curve.

In the environmental tests, the specimens (of thickness $6,4.5$ and $3 \mathrm{~mm}$ ) were loaded to predetermined displacements and immersed in environmental containers attached to the cracking apparatus. The fluids were refilled every 2 days and the growth of the crack observed through the eyepiece graticule of a $\times 50$ microscope at suitable time intervals. The load relaxation indicated by the dial gauge reading was recorded as a function of time and crack extension. A crack growth curve may be generated in terms of the time of immersion. Fig. 11 shows a typical curve for crack growth in PMMA as a function of time in ethanol under a

*This crack propagation apparatus was devised by Professor Charles Gurney. 
DIAL GAUGE

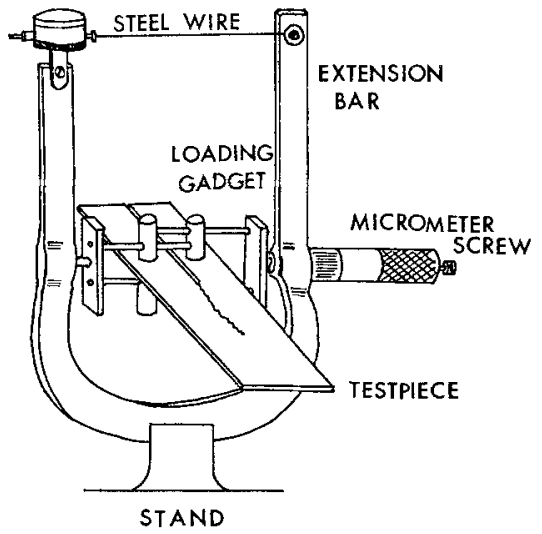

Figure 10 A simple crack propagation apparatus.

constant displacement of $7.3 \times 10^{-2} \mathrm{~cm}$. Instantaneous crack speed may be derived by differentiation of this curve at the position where the corresponding fracture toughness is readily calculated from

$$
R=-\frac{u}{2 t}\left(\frac{\partial X}{\partial L}\right)_{v}
$$

where $u$ is the displacement, $t$ the net section thickness and $(\partial X / \partial L)_{u}$ the load relaxation as the crack extends at constant $u$.

Alternatively, when there was appreciable crack growth, the specimen could be unloaded and the average fracture toughness of the material in the environment determined from the method described in [11]. The corresponding average crack speed was obtained by dividing the crack length increment with the time of immersion.

Most of the tests were performed on DCB (Double-Cantilever Beam) testpieces with shallow face grooves so that crack propagation was controlled directionally. A thin layer of silicone grease was coated on the faces to prevent surface crazes. For experiments in which cracks grew at very slow speeds $\left(<10^{-3} \mathrm{~mm}\right.$ $\mathrm{sec}^{-1}$ ), glass plates ( $3 \mathrm{~mm}$ thick) were coupled onto the specimen surfaces during the test so as to eliminate any excessive creeping effects.

Fig. 12a to $\mathrm{d}$ show some of the typical results on the cracking of PMMA in octane, benzene, ethanol and $\mathrm{CCl}_{4}$. The temperature at which the experiments were performed was listed in the figures. It should be noted that in Fig. 12b, the material at the crack tip has gone into the solution of benzene. Table II gives some typical
TABLE II Comparison of fracture toughness of PMMA in various environments under constant displacement tests

\begin{tabular}{llll}
\hline Environment & $R\left(\mathrm{~kJ} \mathrm{~m}^{-2}\right)$ & $\dot{L}\left(\mathrm{~mm} \mathrm{sec}^{-1}\right)$ & $R_{\text {air }} / R_{\text {environ }}$ \\
\hline Benzene & 0.010 & $1.59 \times 10^{-3}$ & 25 \\
Ethanol & 0.018 & $5.5 \times 10^{-4}$ & 14 \\
Carbon & & & \\
tetrachloride & 0.053 & $2.19 \times 10^{-4}$ & 3 \\
Octane & 0.256 & $2.20 \times 10^{-3}$ & 1.20 \\
\hline
\end{tabular}

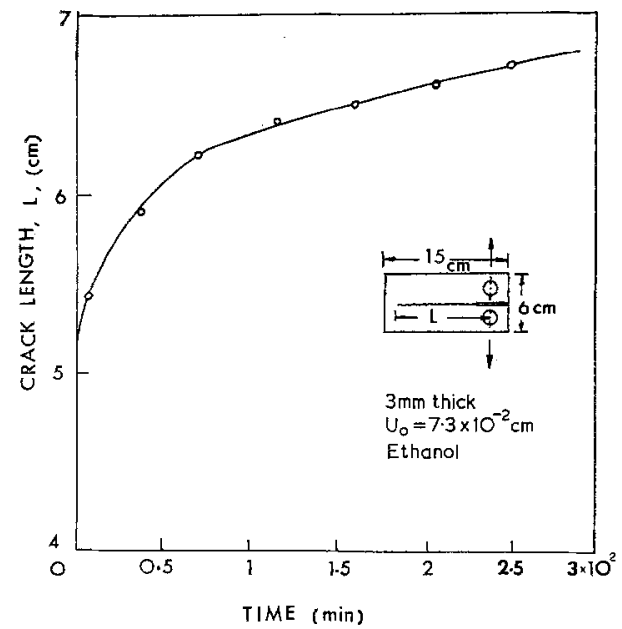

Figure 11 Crack growth of PMMA in ethanol under constant displacement.

fracture toughness values in the various liquids and their corresponding crack velocities at 296 to $298 \mathrm{~K}$. A comparison with the toughness values in air and at similar crack velocities is also included.

\section{Discussion}

\subsection{Crack initiation toughness and fracture in virgin specimens}

Following the arguments of Andrews and Bevan $[1,2]$, because good correlations between $\sigma^{2}$ and $\left(Y^{2} L\right)^{-1}$ are obtained for experiments performed in each of the liquid environments, (such as shown in Fig. 3), we believe that the discontinuities propagated are true cracks and not crazes. Andrews and Bevan [2] have presented $\mathscr{T}_{0}$ values (equivalent to $R_{\mathbf{i}} / 2$ ) for PMMA in ethanol and carbon tetrachloride at some small loading rates as a function of temperature. However, to compare their data with the present results is difficult because we do not know the strain rates for their experiments. The smallest crack initiation toughness value in 

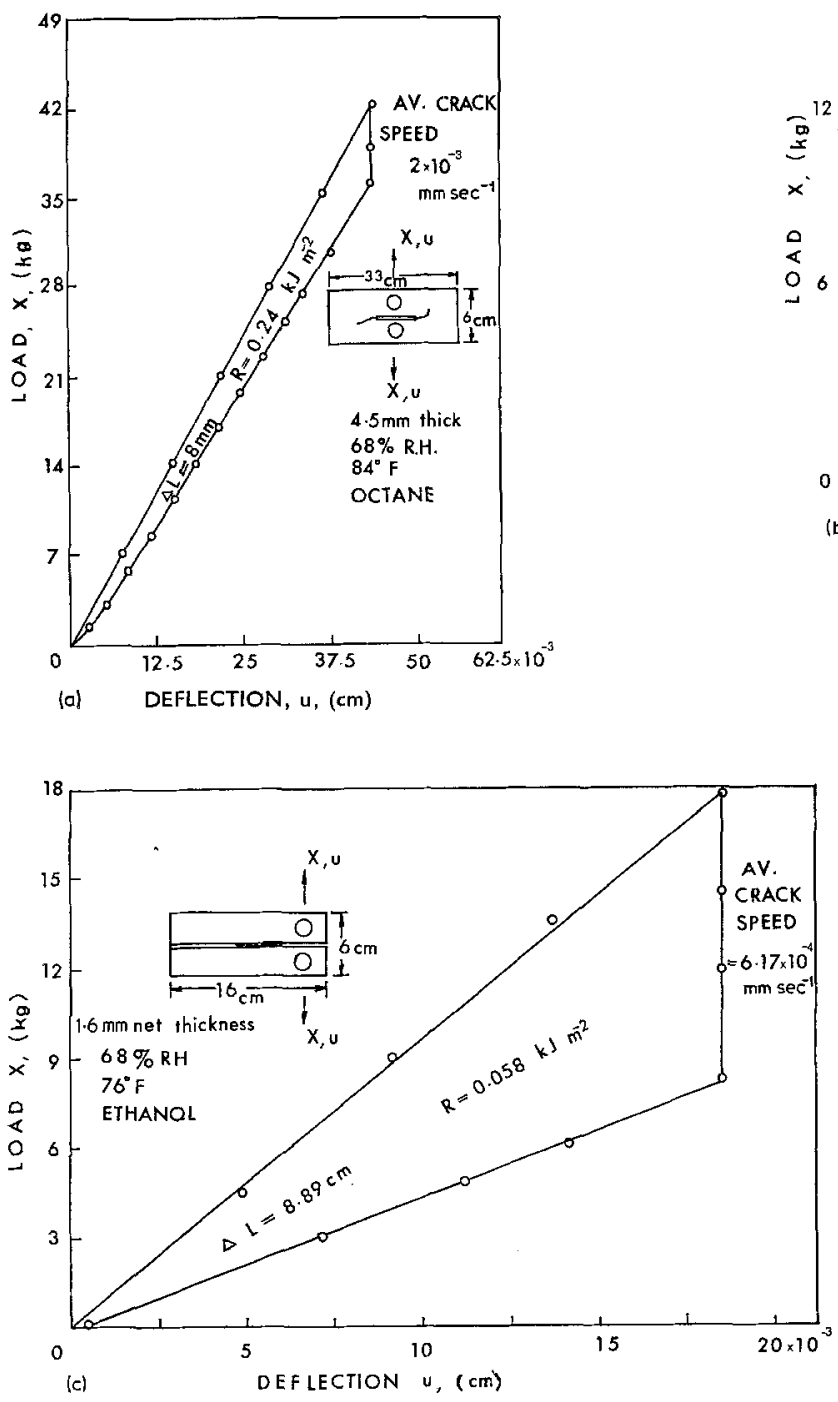
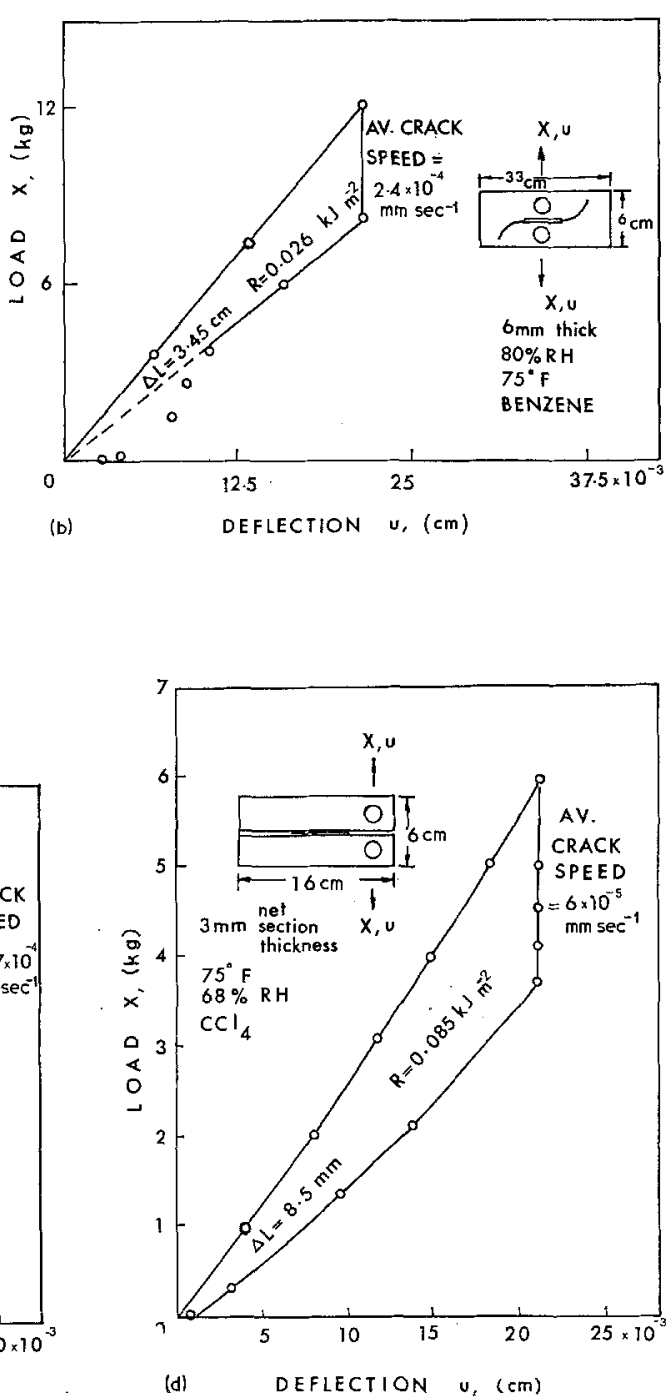

Figure 12 (a) to (d) Fracture toughness measurements of PMMA under constant displacements when immersed in (a) octane, (b) benzene, (c) ethanol and (d) carbon tetrachloride.

ethanol at $296 \mathrm{~K}$ obtained in our experiments is 4 $\mathrm{J} \mathrm{m}^{-2}$ (at a strain rate of $5 \times 10^{-4} \mathrm{~min}^{-1}$ ) and is somewhat greater than the value $\left(2 \mathscr{T}_{0}=2.5 \mathrm{~J}\right.$ $\mathrm{m}^{-2}$ ) at the same temperature reported by Andrews and Bevan [2].

The idea of a critical local stress [5] for environment-enhanced crack initiation leads to a replot of the data presented in Fig. 5. This is shown in Fig. 13 in which $K_{\mathrm{m}}\left(=\sigma Y L^{1 / 2}\right)$, the crack tip stress intensity factor at initiation, is plotted against $\log _{e} \dot{\epsilon}$, where $\dot{\epsilon}$ is the strain rate. For convenience, only data for the single edgenotched specimens are used. $\dot{\epsilon}$ is obtained by dividing the cross-head speed $(\dot{u})$ with the gauge length $(=10 \mathrm{~cm})$ which is measured between

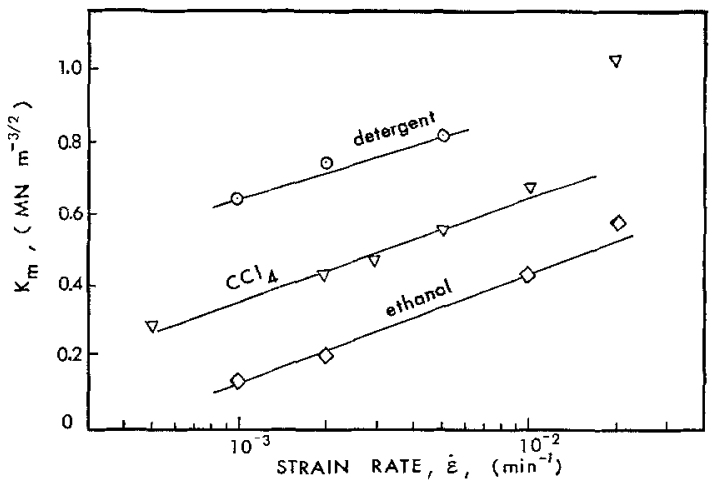

Figure 13 Effect of strain rates on $K_{\mathrm{m}}$ for PMMA immersed in ethanol, $\mathrm{CCl}_{4}$ and detergent. 
clamping positions. It is obvious that a ReeEyring equation of the form

$$
\dot{\epsilon}=B \exp -\left(U-b K_{\mathrm{m}}\right) /(k T)
$$

fits the data very well over the range of strain rates investigated. In Equation $5, B$ and $b$ are constants; $U$ is the activation energy and $k$, Boltzman's constant. It is, therefore, important to realize that, like some low density polyethylenes [20], $R_{\mathrm{i}}$ or $K_{\mathrm{m}}$ of PMMA is strongly rate (or $\dot{u}$ ) dependent. This relatively significant point has not been discussed in previous work on environmental craze or crack initiation in PMMA.

As pointed out by Andrews and Levy [3], there are obvious difficulties in applying the concept of a $K_{0}$-dependent craze velocity [4] to interpret fracture results in virgin specimens such as those described in Section 2.3.1. These

Figure 14 (a) Schematic drawing showing details of fracture surface in liquid environments. (b) Crack initiation (region $\mathrm{A}$ ) and generation of crazes (region $\mathrm{B}$ ) in $\mathrm{CCl}_{4}, \times$ 40. (c) Surface roughening during stable cracking in $\mathrm{CCl}_{4}, \times 40$. (d) Unstable cracking (region $\mathrm{C}$ ) in $\mathrm{CCl}_{4}, \times 40$.
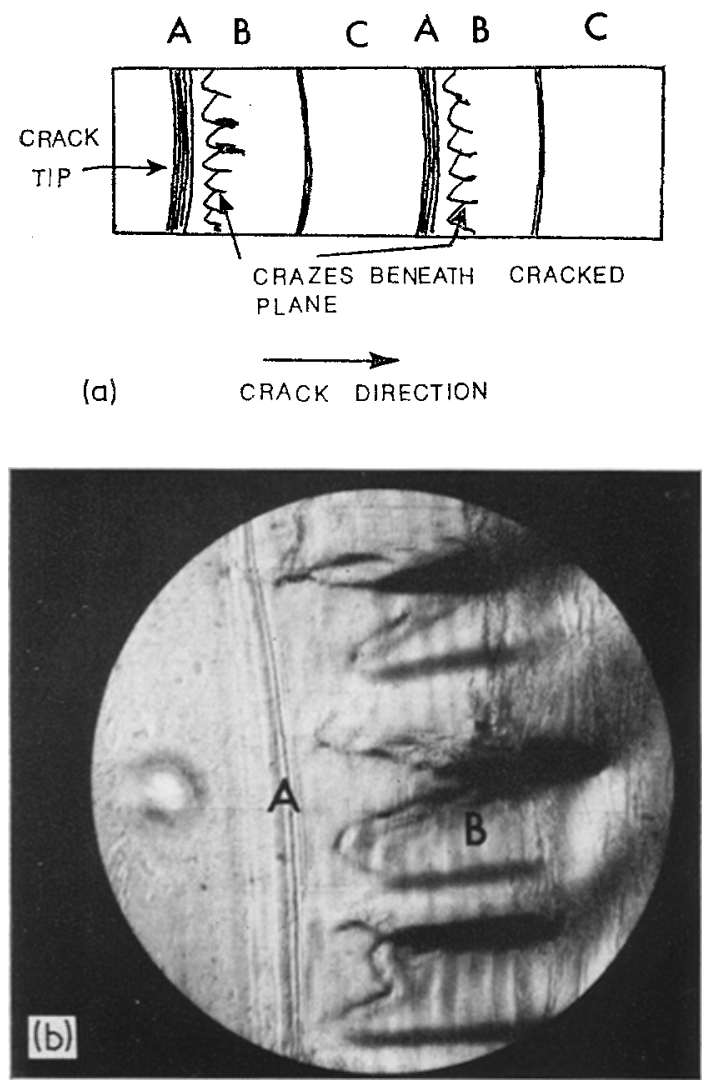

experiments show that crazes do initiate and propagate (from all sides) inwards at reasonable constant velocities on about the same plane and cause eventual fracture. The "equivalent crack" theory developed in $[2,5]$ may, therefore, be a useful alternative for the present analysis. To account for the increase of fracture life $\left(t_{f}\right)$ associated with geometrically larger specimens, three assumptions are made. (1) The equivalent crack lengths $(l)$ of the natural solvent crazes in ethanol and carbon tetrachloride are independent of specimen size and of the order of 0 to 0.3 $\mathrm{mm}$ [5] and do not change as the crazes grow. (2) Under an applied stress, the characteristic behaviour where the crazes grow at constant velocity is established $[4,5]$. (3) When the stress acting over the uncrazed area reaches a critical value failure of specimen occurs. Based on these not unreasonable assumptions, it may be proved
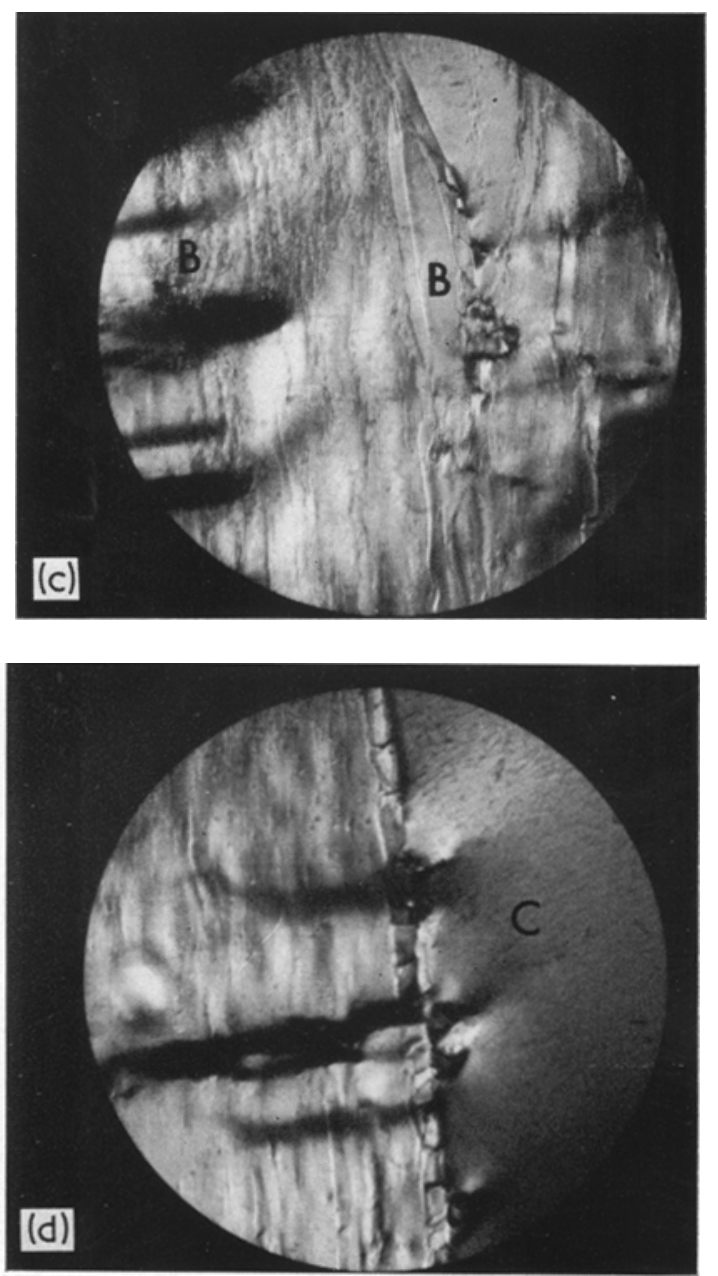
that the crazed area before fracture in the geometrically larger specimen is $n^{2}$ times that of the smaller specimen, where $n$ is the scaling factor. When $l$ is small compared to the dimensions of the crazed area at the moment of fracture, and when craze velocities are only dependent on the applied stress [5], the fracture time $\left(t_{\mathrm{f}}\right)$ for the bigger specimen is roughly $n$ times that of the smaller one. In our experiments, $n=1.5$; however, the actual value obtained from the results (Fig. 9) is about 2 to 2.5. This discrepancy is probably due to the thickness effect on craze velocity because thicker specimens have lower craze velocities at the same applied stress levels [4].

\subsection{Fracture surfaces and crack front geometries in environmental fracture of PMMA}

Fig. $14 \mathrm{a}$ is a schematic drawing showing the three-stage cracking mechanism as observed in a typical monotonic load to fracture test. These are conveniently described as (i) the initiation or onset of crack growth, (ii) the slow and stable cracking stage involving the creation of crazes and wrinkles near the crack tip and (iii) the unstable cracking stage. Fig. $14 \mathrm{~b}$ to $\mathrm{d}$ show the details of each of these stages when PMMA is fractured in carbon tetrachloride at $296 \mathrm{~K}$. The onset of crack growth (region A in Fig. 14b) occurs at very small initial loads due to the weakening of the crack tip material by the environment. This usually includes a steady crack growth of about 0.25 to $2 \mathrm{~mm}$. When crazes are established at the crack tip, to further propagate the crack in a stable manner, additional work must be supplied to shear off the crazes at different planes ahead of the crack tip and simultaneously to generate new craze cavities further away. Naturally, this will produce roughening or level differences on the fracture surface as shown in Fig. 14c. Methods of making cracks spread along distances stably in this phase have been discussed in Section 2.2. The fracture surface corresponding to the unstable phase is shown in Fig. 14d, region C.

The crack front configurations of PMMA during propagation depend largely on the environments used. It is interesting to note that while benzene produced a concave crack front in the propagation process, carbon tetrachloride yielded, in contrast, a convex crack front geometry. This suggests that in a more aggressive fluid such as benzene the crack starts from the external surfaces and hence propagates at a speed faster than the internal material. Conversely, for relatively weaker solvents such as $\mathrm{CCl}_{4}$, kerosene and gasoline, and at comparable testing conditions, the crack starts internally and gives a parabolic crack front geometry. It seems that the "end flow" or "side flow" postulates [4] do not necessarily follow in these experimental results. Perhaps this can best be explained by the fact that swelling has introduced a high internal tensile stress in the mid-thickness of the testpiece while the surface layers are weakened alongside with a reduction of the stress they originally have to withstand [21]. It is only necessary to assume that for benzene, the weakening effect dominates and the crack starts on the surfaces; whereas for $\mathrm{CCl}_{4}$, the crack starts internally when the high tensile stress set up in the interior of the testpiece reaches a critical stress level for propagation.

It is also worth mentioning that in some very slow speed experiments $\left(<10^{-3} \mathrm{~mm} \mathrm{sec}^{-1}\right)$ using face-grooved DCB testpieces, the crack proceeds through the softened crazes in a zig-zag manner all along the groove.

\subsection{Fracture toughness-crack velocity relationship}

It has been shown by Marshall et al. [20, 22], Mai [7, 23] and Lee [24] that the crack tip stress intensity factor $(K)$ or the fracture toughness $(R)$ is a useful parameter to characterize crack speeds for a given polymeric material in a constant environment and stress situation. Fig. 15 summarizes the results of the fracture toughness of PMMA in ethanol and carbon tetrachloride as a function of crack velocity at 296 to $298 \mathrm{~K}$. The corresponding air results [25] are also included. It is obvious that in the high crack speed range $\left(>10^{-2} \mathrm{~mm} \mathrm{sec}-1\right)$, the fracture toughnessin the environments is greater than that in air because additional work other than that necessary for cracking unit area of material is required to rupture and regenerate craze cavities near the affected crack tip region. In the low velocity range $\left(<10^{-2} \mathrm{~mm} \mathrm{sec}-1\right)$, the fracture toughness in the environments has lower magnitudes, probably because the crack grows within the solvent-induced craze structure and thus needs less energy for its propagation. The high speed range data were obtained from monotonic increasing displacement tests performed in the Instron as discussed in Section 2.2 and the low speed range toughness values were derived 


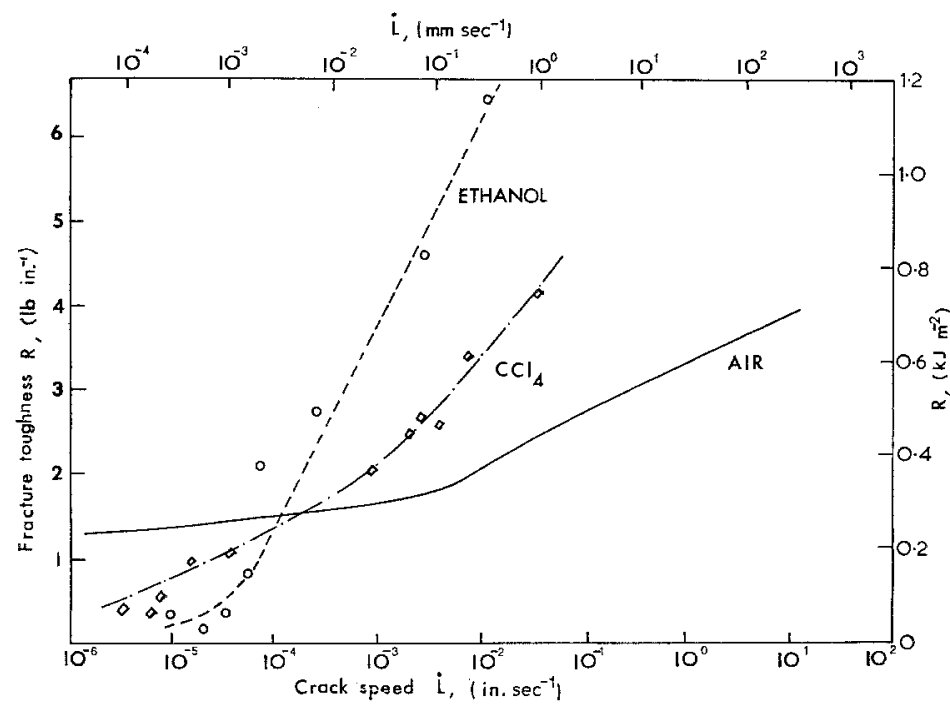

Figure 15 Variation of fracture toughness with crack velocity in air, ethanol and carbon tetrachloride. from the constant displacement experiments using the sample crack propagation apparatus. Attempts to generate higher crack velocity data $\left(>10 \mathrm{~mm} \mathrm{sec}^{-1}\right.$ ) were not successful because of the enormous craze bundles formed at the crack tip neighbourhood which produced severe instability as the crack extended beyond them.

From the data presented for these two organic solvents, it is important to realize that there exist unique relations between $R$ and $\dot{L}$ during crack propagation. Although it is tempting to believe so, we do not have enough data at the time of writing to show that similar relations also exist in other liquid environments.

\section{Conclusions}

The fracture behaviour of PMMA in a number of liquid environments such as $\mathrm{CCl}_{4}$, ethanol, water, kerosene, etc, and under the application of monotonic increasing displacement (i.e. in an Instron), constant loads and constant displacements has been discussed. Fracture mechanics concepts are used successfully in the analysis of the results. It has been shown that the crack initiation toughness is rate sensitive and environment dependent. Further, the fracture toughness of PMMA such as in carbon tetrachloride and ethanol may be obtained as a function of crack velocity.

Continuing experiments are being performed in Michigan to obtain more information on the micro-mechanisms controlling environment-enhanced fracture in PMMA. It is expected that these results will be reported soon.

\section{Acknowledgements}

The author is grateful to Professor H. C. H. Gurney for his supervision and many helpful discussions during the period of this research carried out at the Department of Mechanical Engineering, University of Hong Kong. Thanks are also due to $\operatorname{Dr}$ A. G. Atkins for helpful comments on the manuscript. A research scholarship provided by the Hong Kong Productivity Centre throughout this work is gratefully acknowledged.

\section{References}

1. E. H. ANDREWS and L. BEVAN, "Physical Basis of Yield and Fracture" (Institute of Physics, London, 1966) p. 209.

2. Idem, Polymer 13 (1972) 337.

3. E. H. ANDREWS and G. M. LEVY, ibid 15 (1974) 599.

4. G.P.MARSHALL, L.E. CULVER and J. G. WILLYAMS, Proc. Roy. Soc. Lond. A319 (1970) 165.

5. E. H. ANDREWS, G. M. LEVY and J. WILLIS, $J$. Mater. Sci. 8 (1973) 1000.

6. A. N. GENT, ibid 5 (1970) 925.

7. Y. W. MAI, Ph.D. Thesis, University of Hong Kong (1972).

8. G. P. Marshall and J. G. Williams, $J$. Appl. Polymer Sci. 17 (1973) 987.

9. Y. W. MAI, J. Mater. Sci. 9 (1974) 1896.

10. J. J. Benbow, Proc. Phys. Soc. B78 (1961) 970.

11. C. GURNeY and J. HUNt, Proc. Roy. Soc. Lond. A299 (1967) 509.

12. C. GURNEY and K. M. NGAN, ibid A325 (1971) 207.

13. C. GURNEY, "Physical Basis of Yield and Fracture" (Institute of Physics, London, 1966) p. 3.

14. C. GURNEY and Y. W. MAI, Eng. Fract. Mech. 4 (1972) 853 . 
15. D. P. CLAUSING, Int. J. Fracture 5 (1969) 211.

16. J. I. BLUHM, "Fracture", Vol. 5, edited by H. Liebowitz (Academic Press, New York, 1969) p. 1.

17. C. L. CHOW and P. M. LAM, J. Eng. Mats. Tech. 96 (1974) 41.

18. W. F. BROWN and J. E. SRAWLEY, ASTM S.T.P. 410 (1966).

19. s. N. ZHUR kov, Int. J. Fract. Mech. 1 (1965) 311.

20. G.P.MARSHALL, L.E. CULVER and J. G. WILLIAMS, Plastics and Polymers 38 (1970) 95.

21. C. GUR Ney and z. Borysowski, Proc. Phys. Soc. A61 (1948) 446.
22. G.P.MARSHALL, L.E. CULVER and J. G. WILLIAMS, Plastics and Polymers 37 (1969) 75.

23. X. W. MAI, Int. J. Fracture 9 (1973) 349.

24. C. S. LEE, Ph.D. Thesis, University of Michigan, Ann Arbor (1974).

25. Y. W. MAI, unpublished research, University of Hong Kong (1972).

Received 7 October and accepted 8 November 1974. 